\title{
PARADIGMA SISTÊMICO APLICADO AO DIREITO
}

\author{
SYSTEMIC PARADIGM APLIED TO LAW
}

Mateus Campos de Lemos*

\begin{abstract}
RESUMO
A essência da pesquisa refere-se ao estudo da viabilidade da inserção do paradigmasistêmico aplicado ao Direito, que emerge de forma a se contrapor ao paradigma cartesiano vigente, este último, já inserido na perspectiva tradicional no meio jurídico.A perspectiva sistêmica preza por uma abordagem humanizada e eficiente da perspectiva do Direito, de forma a convergir diretamente com a concepção de justiça multiportas promovida pelo Código de Processo Civil vigente, bem como pela Resolução 125 do Conselho Nacional de Justiça. Para o estudo, inicialmente é necessário compreender a acepção conceitual de paradigma, bem como discorrer acerca do paradigma cartesiano, sua inserção ao Direito tradicional vigente e suas mazelas, o que conduz inicialmente a uma nova compreensão de acesso à justiça, conduzida pela Lei $\mathrm{n}^{\circ}$ 13.105 e pela Resolução 125 do Conselho Nacional de Justiça. Em sintoniacom a nova acepção de acesso à justiça, se estuda acerca da origem e das técnicas relacionadas à perspectiva sistêmica, como proposta de novo paradigma vigente ao Direito. Realiza-se, para tanto, pesquisa bibliográfica, revisão de literatura, bem comopesquisa documental com a coleta de dados de instituições especializadas. Nesse sentido, apurou-se a devida adequabilidade da inserção da perspectiva sistêmica aplicada ao Direito, através de diversas ferramentas e métodos analisados, a adesãoao paradigma sistêmico demonstrou ser também forma garantidora de uma nova acepção de justiça, mais célere e efetiva por vezes, do que o modelo tradicional jurisdicional.
\end{abstract}

Palavras-chaves: Paradigma Sistêmico. Justiça Multiportas. Meio Adequados de Solução de Conflitos. Constelação Familiar.

\begin{abstract}
The essence of the research refers to the study of the feasibility of inserting the systemic paradigm applied to Law, which emerges in opposition to the current Cartesian paradigm, the latter already inserted in the traditional perspective in the legal environment. The systemic perspective values a humanized and efficient approach to Law, in order to directly converge with the concept of multi-door justice promoted by the current Code of Civil Procedure, as well as by Resolution 125 of the National Council of Justice. For the study, it is initially necessary to understand the conceptual meaning of paradigm, as well as to discuss the Cartesian paradigm, its insertion into the current traditional Law and its ills, which initially leads to a new understanding of access to justice, conducted by Law No. 13.105 and by Resolution 125 of the National Council of Justice. In line with the new meaning of access to justice, the origin and techniques related to the systemic perspective are studied, as a proposal for a new paradigm in force in Law. Therefore, bibliographical research, literature review, as well as documentary research with data collection from specialized institutions are carried out. In this sense, the appropriateness of the insertion of the systemic perspective applied to the Law was verified,
\end{abstract}

Artigo submetido em 07 de agosto de 2021 e aprovado em 07 de setembro de 2021.

*Graduando em Direito pela Pontifícia Universidade Católica de Minas Gerais. E-mail: mateuscampos.jus@gmail.com 
through various tools and methods analyzed, the adherence to the systemic paradigm also proved to be a guaranteeing way of a new sense of justice, faster and more effective at times, than the traditional jurisdictional model.

Keywords: Systemic Paradigm. Multi-Door Justice. Suitable means of Conflict Resolution. Family Constellation.

\section{INTRODUÇÃO}

A ciência, nada mais é, do que uma exploração contínua de pensamentos, de forma a se questionar, de se indagar e de derrubar conceitos preconcebidos, a alma da ciência é a mudança, com o intuito de aprimorar sempre a visão de mundo. A forma como a sociedade compreende, analisa e se organiza no cotidiano, está diretamente relacionada à adoção de paradigmas vigentes.

Não o é diferente na seara do Direito, uma vez que este, historicamente, esteve entrelaçado ao paradigma científico cartesiano, sempre em busca do preceito de uma verdade una, a ser alcançada juridicamente, zelando sempre também, pela segurança jurídica como questão primeira. A norma positivada e a jurisdição, sob perspectiva cartesiana, seriam, portanto, os únicos meios seguros para se apaziguar os conflitos sociais e se alcançar à justiça. Diante disso, com o desenvolver da sociedade moderna hiper complexa, as respostas jurisdicionais e os textos normativos passaram a não mais solucionar os conflitos de forma adequada. O tecnicismo e o formalismo exacerbados desagradam com uma evidente ausência de celeridade e eficácia, de maneira que se clama por um novo formato de acesso à justiça, não mais vinculando, necessariamente, à jurisdição tradicional, havendo, portanto, outros modos de acesso à justiça digna.

É nesse sentido que emergem novas concepções acerca do que é, de fato, a justiça, e como ela pode ser alcançada através dos demais meios de resolução de conflito, não sendo, portanto, o Direito tradicional cartesiano, meio uno de desenvolvimento e solução do litígio. Os novos desafios no âmbito do Direito aparentam ser, portanto, a descoberta de métodos e dinâmicas outras, que correspondam à inclusão de características, sentimentos e demais fatores subjetivos, que devam ser considerados como intrínsecos ao contexto do conflito, emergindo, portanto, o paradigma sistêmico aplicado ao Direito.

\section{DO PARADIGMA CARTESIANO APLICADO AO DIREITO}

Inicialmente se faz necessário tecer acerca da definição conceitual de paradigma, o termo, "paradigma", é usualmente empregado no vocabulário das ciências humanas (AMORIM, 2011), ademais seu estudo merece ainda especial estima na contemporaneidade, visto que "parece haver atualmente certo modismo na utilização da palavra paradigma. A causa disso é, sem dúvida, a situação do ocidente capitalista, uma época de decadência e de reorganização das visões de mundo." (AMORIM, 2011, p. 346).

Na semântica do termo, identifica-se no dicionário que o termo "paradigma" se mostra definido como "algo que serve de exemplo geral ou de modelo" (DICIONÁRIO PRIBERAM DA LÍNGUA PORTUGUESA, 2021), e, em sentido gramatical, como "conjunto das formas que servem de modelo de derivação ou de flexão" (DICIONÁRIO PRIBERAM DA LÍNGUA PORTUGUESA, 2021).

Aparenta ainda ser mais didática a definição de paradigma proposta por Fritjof Capra (2014), como "uma constelação de conceitos, valores, percepções e práticas compartilhadas por uma comunidade, formando uma visão particular da realidade que é a base da maneira pela qual a comunidade se organiza." (CAPRA, 2014, p. 80). 
O surgimento do paradigma em destaque, o cartesiano, está necessariamente vinculado com a história da ciência, a cientificidade emerge na modernidade (século XVI) quando "a revolução no pensamento, levada a cabo pelas descobertas científicas de Copérnico e Galileu, rompeu com o paradigma até então em vigor (universo finito, com Deus em seu epicentro)" (ARAÚJO, 2009, p. 79). Nessa época, o conhecimento estava mitigado e carregado até então pelo caráter teológico, não se permitindo propriamente a existência do conhecimento científico pleno (ARAÚJO, 2009).

Em 1.637, na célere obra $O$ Discurso do método, o pensador francês René Descartes consagra em sua publicação o método dedutivo cartesiano, que marcou a forma de se pensar racionalmente e alvoreceu a implementação do Paradigma Cartesiano. Explica-nos Thomas Kuhn, que o paradigma (cartesiano) que teve vigência até os dias atuais foi "iniciado por Descartes e desenvolvido na mesma época que a dinâmica newtoniana. Esse paradigma serviu tanto à ciência quanto à filosofia." (KUHN, 2006 apud GRAÇA, 2012, p. 51).

O discurso cartesiano foi fundamental para a soberania da ciência perante influências da ordem religiosa, uma vez que propôs construir um discurso que se valia apenas da autonomia pelo raciocínio dedutivo. "Descartes pretende, com a elaboração de seu método, alcançar a verdade, eliminando, para tanto, duas atitudes que considera infantis: a prevenção e a precipitação" (ARAÚJO, 2009, p. 80). De forma simplificada, pode-se afirmar que o pensamento cartesiano "prioriza o processo analítico, em que se espera a compreensão dos objetos com cla delimitação de suas fronteiras e com a sua decomposição, visando à simplicidade e ao reducionismo" (BAGGENSTOSS, 2018, p. 155). A intenção de Descartes foi: "propor uma visão a partir da análise e da síntese, com enfoco observacional das partes particulares de um todo, em busca do entendimento racional (LAKATOS; MARCONI, 1991 apud BAGGENSTOSS, 2018, p. 155).

Pode-se dizer que a dinâmica cartesiana influenciou, e ainda influencia, o método científico em seus vários ramos, nas ciências sociais, biológicas, exatas, entre outras áreas do conhecimento que buscam cada vez mais aprofundar em ramos específicos de estudos. Vê-se mui presentes os postulados cartesianos à medida que vivemos em meio à "incessante busca por critérios de avaliação plasmados em fórmulas, tabelas, gráficos e regras que, quanto mais precisos, mais dotados de cientificidade estarão" (ARAÚJO, 2009, p. 80). Todavia, para enfoque da presente pesquisa, é salutar analisar como as ciências sociais transplantaram o método científico em seu campo de atuação, especialmente no âmbito do Direito.

Através da inspiração dos pressupostos do paradigma cartesiano, as ciências sociais transplantaram o método científico próprio das ciências exatas para o seu campo de atuação, de forma a conduzir a disseminação da expressão "física social". (ARAÚJO, 2009). Nas palavras de Rodrigo Valadão, "enquanto as ciências exatas têm como linguagem a própria representação matemática da realidade, a ciência do direito tem como linguagem específica a moldura oferecida pelo texto normativo" (VALADÃO, 2002, p. 310). "Foi Comte que criou o termo sociologia para se referir a essas ciências da sociedade humana, que deveria seguir o exemplo das demais ciências positivas e de se desenvolver uma "física social". (VASCONCELLOS, 2018, p. 96).

O Direito, portanto, só pode ser pensado uma vez percebido e respeitado sua raiz no pensamento cartesiano e newtoniano, as implicações ideológicas e práticas aplicadas ao campo do Direito são totais. É através do paradigma cartesiano que se compreende os surgimentos das teorias de matriz positivista, bem como da origem do tecnicismo que permeia o pensamento jurídico-normativo e da instrumentalização que se tem sobre o Direito (GRAÇA, 2012).

Há aqueles que afirmam sobre a disseminação da perspectiva cartesiana aderir-se ao Direto no começo do século XIX, consolidando-se com Hans Kelsen no século XX (RUZON, 2011). Segundo Karl Larenz "na sua Teoria Pura do Direito, Kelsen reivindica para a ciência jurídica, à semelhança da lógica e da matemática, um objeto puramente ideal, restringindo-a ao 
simples campo do racional necessário" (LARENZ, 1997 apud RUZON, 2011). Assim sendo, tem-se um cenário em que o Direito se vincula com a ideia de verdade una, adotando sempre para tal a metodologia cartesiana, plasmado nas ciências humanas pelo positivismo, sendo um personagem notável a esta lógica Hans Kelsen. (RUZON, 2011).

A lógica por trás do paradigma cartesiano conduziu, cada vez mais, a busca fervorosa na esfera jurídica por um dogma consagrado pelos operadores do Direito: a segurança jurídica. Não poderia ser diferente, uma vez que a "busca pela exatidão científica, destituída de cargas valorativas, influenciou diretamente a definição associada ao positivismo jurídico." (ARAÚJO, 2009, p. 79). O conceito e esperança sobre a perspectiva cartesiana incorporada ao Direito, igualmente à busca pela verdade pura e inabalável, é tão intensa que, ao menos no âmbito do processo penal, torna-se, inclusive, amparada como um princípio, o da verdade real.

A consagração da corrente de pensamento cartesiana aplicada ao Direito é clara, quando se analisa ad exemplum os dizeres que a atuação do julgador pode ser desprovida de subjetividade, uma vez que deve se adstringir em retratar apenas o preconizado na legislação (ARAÚJO, 2009, p. 79). "É o julgador, enfim, conforme as célebres palavras de Montesquieu, a boca da lei." (ARAÚJO, 2009, p. 81).

Pode-se dizer que a imersão radical do cartesianismo acabou por criar autonomia não só da religião, costumes ou demais vícios, mas também autonomia perante outros saberes que não fossem estritamente científicos, de forma a afastar quaisquer demais conhecimentos que não se originassem de prova laboratorial e matemática (GRAÇA, 2012).

Os avanços no estudo da Psicanálise fortificam também o entendimento de que já é ultrapassada a crença de uma razão destituída da subjetividade e da valoração uma vez que, enquanto sociedade e humanidade, somos dotados e influenciados por sistemas multicausais, difíceis de serem dosados pelo método cartesiano (ARAÚJO, 2009).

Nessa perspectiva, acrescenta Aury Lopes Jr: (2006, p. 295): “chegado o momento de resgatar a subjetividade e compreender - recordando as lições de Antônio Damásio - que a racionalidade é incompleta e resulta seriamente prejudicada quando não existe nenhuma ligação com o sentimento." Já no campo filosófico, pode-se amparar também na doutrina de Karl Popper, este se manifesta contrário à verdade ser submissa ao conhecimento e método científico, "para o referido filósofo, a coerência de uma formulação científica afere-se pela sua falseabilidade, isto é, a possibilidade de ser falsa. É a submissão da teoria à refutação que lhe confere cientificidade" (ARAÚJO; 2009, p. 82).

O raciocínio vincula-se a temática do Direito, uma vez que a jurisdição aborda e trata questões relacionadas à solução do litígio, há autores que já apontam ser inadequada a visão cartesiana para tal fim, tendo em vista que "a resolução não está somente em partes ou processos de forma isolada, sendo necessária a unificação de um todo, através de uma interação dinâmica dos envolvidos" (ALVES, 2012 apud BAGGENSTOSS, 2018, p. 160).

Pode-se dizer que, o Direto, ao acolher o método cartesiano, sua metodologia e princípios, acabou também por fazer emergir as mazelas desta metódica, acerca do tema, Pellegrini e Simioni (2015) enriquecem nos dizeres: "A herança desse paradigma tradicional para o campo do direito se reflete na sua instrumentalização, bem como no seu apego exacerbado ao formalismo, ao procedimento, visando sempre uma determinada certeza e logicidade" (PELLEGRINI; SIMIONI, 2015, p. 124), complementam as autoras que "Em nome de uma segurança jurídica que não condiz com a complexidade do direito e das relações do mundo moderno, passam-se a adotar fórmulas gerais e abstratas, na busca de uma epistemologia universal” PELLEGRINI; SIMIONI, 2015, p. 124).

Há de se falar também, da crise jurisdicional relacionada ao excesso de demandas, uma vez a jurisdição adotando a compostura cartesiana e emanando para si como via exclusiva de solução de conflitos, o Estado acabou por não suportar o excesso de demandas cada vez mais 
numerosas e complexas, de forma a refletir na atual jurisdição uma nítida afronta aos princípios da economia processual e duração razoável do processo.

Resta em cristalina decadência o entendimento de ser a máquina estatal, detentora do monopólio para responder às soluções em litígios, bem como diante da incapacidade do Estado (financeira e eficiente) em compensar a contínua e crescente demanda de ações, fica claro ser necessário, portanto, repensar o conceito de atividade jurisdicional em si (BUNN, 2015).

Há autores que perceber uma solução através da demanda por uma nova concepção de conflito, referindo-se à se à necessidade do abandono da visão de litígio analisado apenas em processos e leis, enviesados de forma isolada, sendo necessário, portanto, ir além e desenvolver soluções que envolvam a organização das partes e interesses, através de uma interação dinâmica entre as partes envolvidas, de forma a abranger um contexto do todo litigante. (ALVES, 2012 apud BAGGENSTOSS, 2018).

O que aparenta ser claro, é que eliminação dos litígios, de maneira legal e justa, é do interesse tanto dos litigantes como de toda a comunidade" (THEODORO JR, 2019, p. 56). Sendo assim, começou-se então a se propor novas formas de solução de conflito, além da jurisdição, para se alcançar a almejada pacificação social, construindo assim, uma nova acepção de acesso à justiça. Esse movimento foi vagarosamente se fortificando e sendo consagrado por novas legislações, atuações extrajudiciais, mas também pelo próprio Estado enquanto propiciador de soluções "alternativas" ao litígio, iniciando assim os primeiros indícios da ruptura do paradigma cartesiano através dos chamados: meios adequados de solução de conflito.

\section{DOS MEIO ADEQUADOS DE SOLUÇÃO DE CONFLITO (MASC)}

Ainda que o instrumento processual seja capaz sim de produzir algum efeito, nota-se que a falta de celeridade e o contínuo acúmulo de causas em juízo, acaba porincentivar a discussão de novas perspectivas de acesso à justiça, emergindo assim aprioridade no fomento do sistema multiportas (DAMASCENO; MACEDO, 2018).

Entende-se como um "sistema multiportas: que a depender do conflito sob análise, as partes são encaminhadas a uma "porta" diferente, correspondente ao método que lhes será mais proveitoso como solução.” (DAMASCENO; MACEDO, 2018, p. 379). Então, em determinadas situações, a maneira mais adequada seria através da mediação, já para outros casos, seria adequada a arbitragem, e ainda, alguns outros casos, a melhor via seria a jurisdição perante o juiz, tudo a depender das peculiaridades do caso concreto (DAMASCENO; MACEDO, 2018, p. 379).

O conceito, originalmente, se referia ao termo "multi-door courthouse" (tribunal multiportas em tradução literal) foi expressado de forma inaugural pelo professor Frank E. A. Sander, do corpo docente da faculdade de Direito de Harvard, durante uma conferência convocada pelo Chefe de Justiça dos Estados Unidos, Warren Burger, o tema foi apresentado através do trabalho "Varieties of Dispute Processing", "variedades de processamento de disputas" em tradução livre (KESSLER, G.; FINKELSTEIN, L. J, 1988 apud COELO; MENDES, 2016).

$\mathrm{Na}$ conferência supracitada, apontavam-se preocupações mui semelhantes ao atual cenário brasileiro, de forma a demandar novas soluções ao litígio, in verbis:

A pauta, na ocasião, voltava-se aos problemas encarados por juízes na administração da justiça, os quais, em parte, eram muito semelhantes àqueles presentes na atual situação do Judiciário Brasileiro: cortes sobrecarregadas em razão de cidadãos que nelas buscavam o remédio para uma gama de angústias e anseios pessoais. De acordo com Burger, o fenômeno se trata de uma transferência aostribunais de incumbências antes 
atribuídas a outras instituições; cria--se uma expectativa no sentido de que, ao Judiciário, cabe preencher o "vazio" decorrente do declínio de instituições como a igreja, a famíliae a unidade das vizinhanças e pequenas comunidades. Como resultado, há uma avalanche de processos judiciais. Médicos são processados por pacientes, advogados são processados por clientes, professores são processados por alunos. Comerciantes, fabricantes e, finalmente, todos os níveis do governo, são processados por inúmeras pessoas. (COELO; MENDES, 2016, p. 386).

É bom frisar que os métodos "não pretendem constituirmecanismos alternativos, mas sim adequados. Os procedimentos utilizados não se prestam - ao menos não essencialmente a "desafogar" o Poder Judiciário e agilizara prestação jurisdicional." (COELO; MENDES, 2016, p. 382). De acordo com o professor Sander (2016):

\footnotetext{
Em geral, nós, advogados e professores de Direito temos tido um únicopropósito no que tange à resolução de disputas. É claro que, como destacado anteriormente, bons advogados sempre tentaram prevenir o surgimento das disputas, mas quando isto não é possível, nóstendemos a presumir que os tribunais são os solucionadores naturais e óbvios de conflitos. Em verdade, há uma rica variedade de processosdiferentes, os quais, eu diria, individualmente ou combinados, podem proporcionar uma resolução de conflitos muito mais “efetiva”.(Tradução nossa). (SANDER, 1976 apud COELO; MENDES, 2016, p. 387).
}

Há de se perceber o sistema brasileiro precisou evoluir, novos mecanismos jurídicos já foram implementados, de forma a viabilizar um cenário presente da justiça multiportas. A Resolução 125/2010 do CNJ (Conselho Nacional de Justiça) e o CPC (Código de Processo Civil) de 2015, refletem uma nova percepção processual e jurisdicional, na qual os meios consensuais são amplamente usados, e inclusive obrigatórios, na sistemática do processo, alterando-se, portanto, radicalmente a maneira convencional de se chegar à conclusão satisfativa da lide. (PERPETUO, et al., 2018).

A busca pela solução mais compatível para cada peculiaridade das disputas, sugere a ideia central do sistema multiportas, que viabiliza às partes e operadores do direito, a refletirem e avaliarem qual o melhor método disponível e adotar a resolução que melhor lhe convém. Embora a mediação, a conciliação e a arbitragem não esgotem os métodos adequados de solução de conflito, são, contudo, os meios mais conhecidos no ordenamento jurídico brasileiro (DAMASCENO; MACEDO, 2018) e compõem, sim, um sistema vigente de justiça multiporta, tanto no âmbito judicial como no extrajudicial, sendo necessário, portanto, compreender e conceituar os métodos aquedados de solução de conflito.

A mediação pode ser compreendida como "um mecanismo de solução de conflitos, no qual um terceiro imparcial e com capacitação adequada, facilita a comunicação entre as partes, sem propor ou sugerir quanto ao mérito, possibilitando o diálogo participativo, efetivo e pacífico" (SALES; CHAVES, 2014, p. 257). A mediação possibilita, através de técnicas próprias, a construção de uma solução satisfatória feita pelas próprias partes, uma vez que as partes conflitantes empoderam-se de forma a identificar e a aprender sobre os conflitos ali vividos, permitindo a criação de soluções criativas e eficazes (SALES; CHAVES, 2014).

O conceito de mediação está também previsto no art. $1^{\circ}$, parágrafo único da Lei 13.140, que apresenta o método como meio adequado de solução de conflito no âmbito da administração pública:

Art. $1^{\circ}$ Esta Lei dispõe sobre a mediação como meio de solução de controvérsias entre particulares e sobre a autocomposição de conflitos no âmbito da administração pública. 
Parágrafo único. Considera-se mediação a atividade técnica exercida por terceiro imparcial sem poder decisório, que, escolhido ou aceito pelas partes, as auxilia e estimula a identificar ou desenvolver soluçõesconsensuais para a controvérsia. (BRASIL, [2021b], art. $1^{\circ}$ ).

Conforme dispõe a legislação pátria, a modalidade da mediação é mais indicada para litígios compostos por partes entre as quais existe vínculo pretérito, ad exemplum, conflitos societários, familiares, domiciliares, condominiais (COELO; MENDES, 2016).

Os conflitos tratados em uma mediação podem ser entendidos como "posições que entram em oposição aos desejos do outro, que envolve uma luta pelo poder e que sua expressão pode ser explícita ou oculta atrás de uma posição ou discurso encobridor" (VAZZULLA, 2001, p.24 apud SALES; CHAVES, 2014, p. 262). Por certo, a mediação representa um processo além da sua resolução ou do acordo, promovendo também a pacificação das relações sociais.

Para se atingir a almejada pacificação entre as partes, o mediador deve utilizar--se de técnicas que permitem a cooperação entre os "litigantes", de forma a permitir aos envolvidos uma cooperação no sentido da resolução do conflito. Destaca-se que o mediador deve possuir expertise para lidar com a complexidade das relações humanas e atuar como uma verdadeira ponte comunicativa (SALES; CHAVES, 2014, p. 263).

É importante destacar, que a mediação se divide em duas escolas, a primeira delas é a escola linear de Harvard, na qual o objetivo primordial é a solução do conflito através do acordo escrito; já a segunda corrente denomina-se como mediação transformativa, onde o acordo não é a finalidade social do método, buscando a primazia do reestabelecimento dos diálogos e laços entres os mediando envolvidos, a fim de se evitar futuros litígios e se conquistar uma pacificação social próspera.

O ordenamento jurídico pátrio adotou a doutrina de Harvard, principalmente a mediação judicial promovida pelo Estado, uma vez que se busca na mediação uma solução à crise judiciária que se enfrenta no Brasil, ou ao menos que consiga garantir maior celeridade aos processos judiciais pendentes. Todavia, não se deve perder de vista o objetivo da restauração da paz social, também cotado pelo Direito (BORGES, et al, 2017), bem como conta-se maior liberdade metodológica quando se aplica a mediação no âmbito extrajudicial.

Já a conciliação trata-se, assim como a mediação, de um processo técnico, autocompositivo e consensual, porém diferencia-se uma vez que o conciliador atua como um terceiro imparcial que, após oitiva das partes, orienta e auxilia os conflitantes, podendo atuar também oferecendo propostas e sugestões para se atingira solução do caso concreto, levando em consideração sempre os interesses das partes e materializando a extinção do litígio. (COELO; MENDES, 2016).

O conceito da conciliação também é consagrado no art. $165 \S 1$, onde demonstra também o campo de atuação preferencial:

$\S 2^{\circ} \mathrm{O}$ conciliador, que atuará preferencialmente nos casos em que não houver vínculo anterior entre as partes, poderá sugerir soluções para olitígio, sendo vedada a utilização de qualquer tipo de constrangimentoou intimidação para que as partes conciliem. (BRASIL, [2021b], art. 161, § $2^{\circ}$ ).

Frisa-se que a conciliação é um método autocompositivo com atuação judicial ou extrajudicial, a diferenciação indica apenas o momento em que ela ocorre, antes ou depois do processo (SALES; CHAVES, 2014). O conciliador, além de conduzir a discussão entre as partes, pode, se for o caso, sugerir soluções compatíveis com o conflito, de forma a conduzir a uma solução que realmente reflita o interesse das partes (SALES; CHAVES, 2014).

Resta claro, que a liberdade de atuação conferida ao conciliador é mais ampla, quando comparada ao mediador, uma vez que lhe é permitido aconselhar as partes e propor dinâmicas 
visando a solução do conflito. (COELO; MENDES, 2016). Contudo, o conciliador, deve estar apto para verificar quando da aplicação da conciliação, uma vez que seu campo de atuação se diferencia da mediação, a conciliação é mais indicada "quando os conflitos são objetivos/patrimoniais, em que, preferencialmente, não existam vínculos afetivos/familiares entre as partes, não sendo necessário um aprofundamento maior na discussão." (SALES; CHAVES, 2014, p. 259).

Não sem motivo, a conciliação vem sendo amplamente utilizada no ordenamento jurídico brasileiro, especialmente na área consumerista, justiça do trabalho e nos Juizados Especiais, de forma a garantir não só mais celeridade, mas oportunizartambém acordos livres e responsáveis, portanto, com maior grau de cumprimento (SALES, CHAVES, 2014).

Adentrando no seguinte método resolutivo, a arbitragem trata-se de uma técnica de solução de conflitos na qual oslitigantes buscam uma terceira pessoa, de sua confiança, imparcial, para dar fim aolitígio, a solução do conflito portanto não é feita diretamente pelas partes, mas sim, pelo árbitro. "A arbitragem, assim como a justiça estatal, é meio adjudicatório desolução de disputas, ou seja, realiza-se mediante heterocomposição. O árbitro, assimcomo o juiz, decide a causa que lhe é submetida." (COELO; MENDES, 2016, p. 380).

É nesse sentido que se compara que, tanto na jurisdição, quanto na arbitragem, as partes adversárias buscam trazer argumentos capazes de gerar o convencimentodo julgador. A decisão final, na arbitragem, não se trata de uma autocomposição e simde uma heterocomposição imposta por um árbitro/juiz. Os conflitantes estão submissos ao resultado declarado pelo terceiro, as partes, limitam--se apenas em apresentar suas razões de convencimento, de forma a convencer uma tendência na decisão final. A arbitragem, então, diferencia-se da jurisdição uma vez que a figura doárbitro é eleita pelos disputantes, bem como o procedimento arbitral é mais flexível enquanto sua forma, porém mais rígido quanto a sua duração.

Importante frisar que "Segundo os parágrafos do art. $3^{\circ}$ do CPC, não conflitamcom a garantia de acesso à justiça a previsão da arbitragem e a promoção estatal dasolução consensual dos conflitos" (THEODORO, 2019, p. 75). Além do mais, a Lei n $9.307 / 1996$, que dispõe sobre arbitragem, demonstrou a desnecessidade de se homologar judicialmente a decisão arbitral, equiparando-se o árbitro, ao magistrado, sendo a decisão por ele proferida, constitui título executivo judicial, consagradotambém este entendimento pelo art. 515, VII do CPC (BORGES, et al, 2017). Veja-se:“Art. 515. São títulos executivos judiciais, cujo cumprimento dar-se-á de acordo com os artigos previstos neste Título: VII - a sentença arbitral.” (BRASIL, [2021b], art. 515, VII).

Ressalta-se que tal mecanismo somente pode ser usado por sujeitos capazes, titulares de direitos patrimoniais e disponíveis" (COELO; MENDES, 2016, p. 382), bem como há de se frisar que a "competência do juízo arbitral, todavia, limita-se basicamente às decisões (inclusive as que determinam medidas cautelares ou coercitivas), não se estendendo à respectiva execução que continuará inserida na atividade privativa do Poder Judiciário" (THEODORO, 2019, p, 76). Dessa forma, restaclaro que a aplicação da arbitragem detém demasiadas limitações, bem como torna- se restrita a uma pequena população, por se restringir a direitos patrimoniais disponíveis.

Os meios adequados de solução de conflitos, outrora apresentados, representam um claro indício e demanda do Direito em se repensar a forma como lidar com os litígios, é compreendendo esta demanda que a legislação pátria, e o próprio Estado jurisdicional, se atualizam ao estabelecer novas formas plurais de solução de conflito, comprometendo-se em uma efetiva pacificação social.

\section{DO PARADIGMA SISTÊMICO APLICADO AO DIREITO}

Com o surgimento da pós-modernidade, a ciência embarcou pela busca de um novo paradigma, um recente padrão geral de concepção do mundo. O paradigma cartesiano não 
demonstrava completude analítica que atendesse aos anseios de uma sociedade pós-industrial, dotada de alta complexidade relacional (ARAÚJO, 2009).

"É assim que a realidade passou a se mostrar em um tal grau de complexidade que a propositura de soluções reducionistas, pautadas pela visão cartesiana, mostrou-se insuficiente." (BAGGENSTOSS, 2018, p. 157). A sociedade contemporânea passou a apresentar um entrelaçamento não linear e não metódico dos fenômenos, surgindo então novos pressupostos epistemológicos como: a complexidade, a instabilidade e a intersubjetividade. (BAGGENSTOSS, 2018).

A perspectiva cartesiana, ao se limitar à concepção de verdade una e imutável, acabou por gerar críticas no âmbito científico, e, inclusive, acabou por gerar novas linhas de pensamentos que condenam toda a pretensão de alcance a uma dita verdade. "Exemplo disso é a doutrina de Karl Popper que se manifesta contrário à ideia de verdade como coerência interna do conhecimento científico" (ARAÚJO, 2009, p. 82). Para o filósofo, toda formulação científica é auferida por ser dotada de falseabilidade, havendo, portanto, sempre a possibilidade de ser falsa, a submissão à refutação que lhe confere o devido caráter científico (ARAÚJO, 2009). Nessa acepção, a ciência contemporânea acaba por criar aversão a alguns ditames cartesianos, uma vez que se percebe a insuficiência deste paradigma diante das novas demandas sociais.

Tendo em vista a deficiência metodológica da perspectiva cartesiana, pode-se afirmar que se ergueu a necessidade de se construir novos paradigmas para o pensamento científico que supram a expectativa hiper complexa das relações humanas vigentes (TRINDADE, 2008 apud BAGGENSTOSS, 2018). Notou-se, portanto, que as soluções dos problemas e conflitos não estavam somente na análise de pequenas partes e processos de forma isolada, seria necessário, portanto, ir além e procurar a resolução na organização e na unificação das pequenas partes, que seria um produto da interação dinâmica de pequenas parcelas que alteram e influenciam o contexto geral dotado de complexidade (ALVES, 2012).

O surgimento de um novo paradigma, conforme outrora abordado, é um movimento natural à evolução epistêmica, sua origem se destina em propor "uma perspectiva pluralista, pela peculiaridade de diversos órgãos e instâncias, que, por suas múltiplas características e funções, podem oferecer respostas diferenciadas e mais apropriadas aos conflitos" (SILVA, 2018 , n.p.). Nesse sentido, se questionou acerca da estruturação dos modos de conhecimentos baseados no paradigma cartesiano, vistos agora como insuficientes, o fez por emergir a concepção sistêmica, dotada de primazia por exames multidisciplinares e de análise ampla ao objeto em análise (BAGGENSTOSS, 2018).

Para Maria José Vasconcellos (2018), o pensamento sistêmico trata-se de umnovo paradigma científico, uma vez que "a ciência está de fato revendo muitos de seus conceitos, mas não chega a essa conclusão pelo abandono do procedimento científico, e, sim, pela descoberta das limitações intrínsecas aos conceitos e métodos que até então utilizava." (VASCONCELLOS, 2018, p. 23). Complementa a autora que, em verdade, o pensamento sistêmico é uma nova forma de ver a ciência, mas não uma nova ciência (VASCONCELLOS, 2018.).

Segundo Capra (2014), a palavra sistema deriva do grego syn+histanai ("colocar junto), "logo o pensamento sistêmico implica uma mudança de perspectiva das partes para o todo, ou seja, a compreensão de que as partes precisam ser colocadas em um contexto, de modo a estabelecer a natureza das suas relações (CAPRA, 2014, p. 94). Com isso, pode-se afirmar que o paradigma sistêmico muito se opõe ao método analítico cartesiano, este último, que separa as partes e as considera isoladamente cada uma para análise.

Pode-se afirmar que sistêmico é entendido "como uma forma de manifestar a realidade, oriunda do século XX, em contraposição "ao pensamento "reducionista-- mecanicista herdado dos filósofos da Revolução Científica do século XVII, como Descartes, Francis Bacon e 
Newton." (BRANCA, 2020, p. 62). Entretendo, é fundamental frisar que a perspectiva sistêmica não nega por completo a racionalidade científica, mas acredita que esta não oferece os parâmetros suficientes para uma devida descrição universal, sendo necessário englobar análises da subjetividade, como a arte, os sentimentos e as tradições espirituais (BRANCA, 2020.).

Pode-se aduzir que o pensamento sistêmico se molda em uma escolamultidisciplinar, que consagra autores e teorias em diversos campos dos conhecimentos. Nesse sentido, Andrade (2014) exemplifica algumas das origens e das atuações sistêmicas na ciência:

\begin{abstract}
Na Escola Sistêmica, então, tem-se - exemplificadamente -, os seguintes autores, construções teóricas, filosóficas e paradigmas: Engenharia de Controle, Eletrodinâmica, Funcionalismo sistêmico social (com Talcott Parcons), Teoria Geral dos Sistemas (por Bertalanffy), Física Quântica, Tradições filosóficas orientais, Gestalt e Linhas sistêmicas de psicologia, Dinâmica de sistemas pela biologia organísmica, Teoria da evolução de Darwin, Estruturas Dissipativas de Prigogine, Hipótese de Gaia, Holismo e Esoterismo, Teoria de Jürgen Habermas, Ecologia, Teoria do Caos, Matemática da Complexidade, Pensamento Complexo (com Edgar Morin), Organizações Sistêmicas Quânticas, em Rede, Teoria das Restrições, Aprendizagem Organizacional, Empresa Viva, Pensamento por Processos, Thinking Design, Teoria U, Teorias Orgânicas Sostemicas, Sistemas Sociais Autopoiéticos (como em Niklas Luhmann), Cibernética (ANDRADE, 2014, p. 87).
\end{abstract}

No campo das ciências sociais, também há autores que desenvolvem ciência a partir da perspectiva sistêmica, ad exemplum, Noberto Bobbio, através da teoria sobre a coerência e a compatibilidade do sistema jurídico (BAGGENSTOSS, 2018), ou ainda Jürgen Habermas, que definia as sociedades como um conjunto sistemáticohiper complexo com constantes alterações nos seus valores-meta (HABERMAS, 2002, p. 18), por fim, pode-se apontar também Niklas Luhmann, o qual apresenta o conceito de sociedade enquanto sistema social e conjunto de elementos comunicativos, este último composto por aspectos linguísticos que promovem a formação sistêmica social (BAGGENSTOSS, 2018).

A implementação deste paradigma se vê não apenas em contínua construção no Direito, más também em seu ápice, uma vez que se demonstra na atualidade uma emergente conjuntura social, "fruto da ruptura do paradigma cartesiano que regeu a modernidade, que demanda um novo Direito, que deve ser plural, prospectivo, discursivo e relativo" (SOARES, 2008, p. 23 apud ARAÚJO, 2009 p. 83). Segundo Silva (2018, n.p.): “é inegável que está acontecendo uma revolução paradigmática ligada ao desenvolvimento de uma nova cultura. Há um claro deslocamento do eixo da Justiça pela inclusão dos meios consensuais no âmbito judicial", complementa o autor, enfatizando também sobre a atuação no âmbito privado: "mas também pela regulamentação e incentivo no âmbito privado, sobretudo considerando as serventias extrajudiciais. Ao estabelecer formas plurais de resolução, o Estado reforça o seu compromisso com a pacificação social." (SILVA, 2018)

O paradigma sistêmico mostra-se atualmente no Direito em um momento mui oportuno, juntamente a uma nova abordagem legal no que se refere aos meios de solução de conflito, incentivada pelo Código de Processo Civil, trona-se clara a intenção do legislador em buscar uma abordagem humanizada e eficiente ao Direito (LIMA; DANTAS; PERANOVICH, 2019). Porém, ressalva Thais Souza que "o movimento consagrado pelo CPC de 2015 que abre as portas para diversas possibilidades de abordagem dos conflitos, e a terceira onda renovatória de acesso à justiça, não forama origem ou a razão para o surgimento do sistêmico." (SOUZA, 2020, p. 8), mesmo assim,segundo a autora, é um forte indicador que demonstra a busca por outros métodos adequados no âmbito jurisdicional (SOUZA, 2020). 
Há autores que relacionam diretamente o surgimento da perspectivasistêmica ao Direito em virtude de uma demonstrada falibilidade da jurisdição, conforme exara Sami Storch acerca da instrução processual tradicional "tende aprovocar cada vez mais o agravamento do conflito e o distanciamento entre as partes, uma vez que, muitas vezes, cada uma delas procura defender o seu direito, combatendo o da outra parte ou mesmo atacando-a pessoalmente (SOTRCH, 2016, p. 305)".

Primordial frisar também que a proposta sistêmica desenvolve uma perspectivamais humanizada dentro das relações tuteladas pelo Direito, uma vez que não se preocupa apenas com as leis, direitos e conflitos judicializados, más sim, valoriza as partes, as pessoas e as suas conexões, como forma efetiva de resolução de conflito,materializando assim, uma nova perspectiva de acesso à justiça. (LIPPMANN; OLDONI; OLDONI, 2018).

Conforme será abordado, o paradigma sistêmico é inserido no âmbito do Direito de diferentes formas, não havendo, portanto, um único método ou uma única técnicaespecífica que simbolize a perspectiva sistêmica como um todo. Nesse sentido, corrobora Alessandra Baggenstoss (2018,) ao explanar que no Direito "o pensamentosistêmico transveste-se de paradigma científico no qual se embasam várias formas restaurativas" de forma que "há várias formas de se promover uma abordagem sistêmica do Direito." (BAGGENSTOSS, 2018, p.171).

Apesar do modelo sistêmico estar em ascensão no Direito e não ser um modelofechado, faz-se necessário demonstrar algumas de suas técnicas, bem como apontar suas devidas diferenciações. Convêm, contudo, apontar que todas as técnicas e movimentos sistêmicos apresentados, convergem no sentido de propor abordagens restaurativas aos conflitos e lides, mesmo que ainda no âmbito processual, de forma a corroborar com a vocação conciliadora emanada pelas novas legislações, como o CPC e a Resolução 125 do CNJ, bem como, valorizando sempre as partes e os aspectos subjetivos inerentes ao conflito. Ratifica Alessandra Baggenstoss nos dizeres:

Sendo assim, e buscando soluções para o problema no judiciário apresentado acima, o novo Código de Processo Civil apresentou em seu texto uma "vocação conciliadora" que sugere que grande parte dos processos poderiam ser resolvidos por meio de conciliação, trazendo o Direito Sistêmico e o exercício da Advocacia Sistêmica como meio para acelerar a resolução de muitos conflitos, desafogando assim, o poder judiciário. Tal forma de pacificar conflitos, afiançada pelo Conselho Nacional de Justiça, apresenta-se, por ora, em conformidade com a Resolução CNJ n. ${ }^{\circ}$. 125/2010, que incentiva o objetivo de tratar situações conflituosas de modo restaurativo. Diante disso e da suposta ligação entre os termos pensamento sistêmico e constelação sistêmica, lançase, como questionamento, qual a relação existente entre pensamento sistêmico, constelações sistêmicas e direito sistêmico. (BAGGENSTOSS, 2018, p. 160).

Feito o questionamento supra, há de se demonstrar alguns conceitos e diferenciações pertinentes à esta nova ceara chamada de sistêmica, especialmente dos comumente termos utilizados como "direito sistêmico", "constelação sistêmica" e "advocacia sistêmica".

Alguns autores empregam o termo Direito Sistêmico de forma abrangente, se referindo a uma forma de visão do mundo, ou ainda, como um ramo epistêmico aplicado ao Direito, sem, contudo, reduzir-se à autoria ou técnica específica. Nessa seara, destaca-se a definição de Pellegrini (2019, p. 3) ao afirmar que "o pensamento sistêmico aplicado ao Direito, coloquialmente chamado de Direito Sistêmico, é a inserção desse novo paradigma da ciência de mudança de visão de mundo e do fazer ciência - no meio jurídico. A autora, prossegue, conceituando Direito Sistêmico citando Damaris (2018):

[...] o Direito Sistêmico pode ser compreendido como um ramo da Ciência Jurídica, que busca e proporciona a viabilidade e o entendimento do Direito 
dentro de uma disciplina de convivência humanizada, tornando-o uma nova possibilidade para a adequação docomportamento humano, não pela coerção, mas pela conscientizaçãoatravés das ordens sistêmicas efetivando uma melhor dinâmica da Justiça e o alívio dos jurisdicionados. [...] A proposta do Direito Sistêmico, é passar a uma nova fase do Direito: sem julgamentos e com maior efetividade aos jurisdicionados pela tomada de consciênciae responsabilização deles mesmos (de cada parte) pelas escolhas ao passo de considerar o Direito como uma ordenação complexa da vidae convivência humana. (BADALOTTI, 2018, n.p. apud PELLEGRINI, 2019, p. 3).

Portanto, para Carolina Pellegrini (2019, p.6) "o Direito Sistêmico pressupõe que o Direito somente cumpre com sua função social quando efetivamente pacifica e reequilibra os desequilíbrios (sistemas) que lhe são provocados a resolver". Desta forma, as ideias oriundas por diversos autores que adotam a perspectiva sistêmica no mundo jurídico, modificou, sobretudo, a forma como os conflitos e a concepção de justiça passaram a ser vistos (PELLEGRINI, 2019), possibilitando "transformar a maneira tradicional com que se conduz e trabalha o fenômeno que é a força motriz para o exercício de qualquer profissão na área jurídica: os conflitos." (PELLEGRINI, 2019, p. 8).

Assim, "o então denominado Direito sistêmico nos propõe a busca de uma solução, não mais focada apenas na ótica competitiva, mas sim cooperativa e pacífica" (GIRARDI; OLDONI; OLDONI, 2018, p. 44), segundo os autores, esta busca sintoniza com a emergente necessidade da pacificação social e da necessidade de se afastar da predominante visão positivista perpetuada no Direito (GIRARDI; OLDONI; OLDONI, 2018).

Outro norte, a expressão "Direito sistêmico" é comumente associada também à perspectiva proposta pelo Magistrado Sami Storch, nesta perspectiva, o Direito Sistêmico estaria relacionado com a análise do direito segundo as teorias propostas pelo filósofo alemão Bert Hellinger, este último, largamente conhecido por cunhar o método terapêutico denominado “constelações familiares", regido pela suposta existência de padrões e repetições que se impõem sobre as pessoas, na forma de leis sistêmicas (STORCH, 2019). Para Sami Storch, o Direito Sistêmico é uma abordagem sistêmica, a qual, só existe direito de fato, quando há uma solução que traga paz e equilíbrio para um determinado sistema complexo de relações, continua Sami Storch:

\begin{abstract}
A expressão "Direito Sistêmico", termo cunhado por mim quando lancei o blog Direito Sistêmico (direitosistemico.wordpress.com), surgiu da análise do direito sob uma ótica baseada nas ordens superiores que regem as relações humanas, segundo a ciência das constelações familiares sistêmicas desenvolvida pelo terapeuta e filósofo alemão Bert Hellinger. A aplicação do direito sistêmico vem mostrando resultados interessantes na minha prática judicante em diversas áreas, notadamente na obtenção de conciliações em processos da Vara de Família e Sucessões, mesmo em casos considerados bastante difíceis, e também no tratamento de questões relativas à infância e juventude e à área criminal (STORCH, 2016, p. 307).
\end{abstract}

Segundo o magistrado, trata-se de uma abordagem sistêmica e fenomenológica, com origens no formato terapêutico da psicologia, o qual, os conflitos e os problemas enfrentados pelas partes, como traumas, dificuldades e bloqueios, se derivam de graves acontecimentos ocorridos não só no passado da vida do indivíduo conflitante, mas também de sua família, em gerações anteriores, e que deixam sua marca e energia no sistema familiar (STORCH, 2016).

Dentre as acepções da expressão "Direito Ssistêmico", esta ganhou maior visibilidade no contexto atual, uma vez que está relacionada com a criação de diversos projetos que visam a implementação da constelação familiar no Tribunal de Justiça, e ainda a criação de diversas 
comissões nas seccionais da $\mathrm{OAB}$, pautadas sempre na perspectiva sistêmica de Bert Hellinger (SOUZA, 2020).

Aparenta ser ideal desenvolver acerca das constelações familiares, em separado, uma vez que esta demonstra-se ser, em verdade, uma técnica terapêutica breve perpetuada no campo da psicologia, não podendo ser reduzida, a sua aplicação, aos regimes do Direito Sistêmico ou ao âmbito do judiciário, evitando assim eventual simplismo da técnica.

De forma sintetizada, a perspectiva Heringeriana proposta por Sami Storch propõe uma análise na perspectiva de que, as questões submetidas ao judiciário vão além do tratamento atual do Direito tradicionalmente exercido, de forma a incluir, portanto, a perspectiva teórica das ordens do amor propostas por Bert Hellinger, bem como a inclusão das constelações familiares utilizadas juntamente com demais métodos adequados de solução de conflitos, como a mediação e a conciliação (SOUZA, 2020).

Outro norte, no que se refere à mencionada terminologia, Direito Sistêmico, "Sami Storch traz essa abordagem como equivalente à única perspectiva sistêmica de análise do Direito, o que não o é" (BAGGENSTOSS, 2018, p. 156). Nesse sentido, merece destaque os perigos acerca da redução da perspectiva sistêmica à abordagem de Bert Hellinger, "deixando de lado qualquer referência a Luhmann e Habermas, os quais analisam o Direito sob o prisma sistêmico, o que não se confunde com a visão sistêmica hellinguerina" (SOUZA, 2020, n.p.). Deve-se, portanto, tecer tais ponderações, de forma a evitar movimentos que além de reducionistas, acabam por excluir autores, perspectivas e técnicas diversas de análise ao Direito (GIRARDI; LIPPMANN; OLDONI, 2018). Nessa lógica, corrobora Alessandra Baggenstoss (2018):

\footnotetext{
A teoria luhmanniana e a habermasiana, por exemplo, dão conta de analisar o Direito sob prisma sistêmico, sem a adoção dos preceitos estabelecidos por Bert Hellinger. Logo, há várias formas de se promover uma abordagem sistêmica do Direito, sem que necessariamente sejam utilizadas as ordens descritas pelo autor alemão. Sobre esse ponto, é importante destacar o seguinte: Bert Hellinger descreveu as denominadas Ordens do Amor (Lei do Pertencimento, Lei da Precedência/Hierarquia e Lei do Equilíbrio), mas não é o criador das Constelações Sistêmicas. (BAGGENSTOSS, 2018, p. 177).
}

Ainda, segundo Alessandra Baggenstoss (2018), quando abordada de forma epistêmica, a temática acerca do termo "Direito Sistêmico" merece notada atenção. Segundo a autora, "Direito, etimologicamente, refere-se à observância, obediência de regras. Contemporaneamente, tem-se como, a grosso modo, um conjunto de normas jurídicas, em sua máxima expressão, que são impostas pelo Estado" (SOUZA, 2020, p.164). Nesse sentido, Direito são normativas que pacificam as expectativas dos sujeitos em relação ao Estado e a sociedade em geral. "Qualquer qualificação a ser acrescida contemplará uma especialização do Direito. Por exemplo, direito penal; direito civil; direito administrativo" (BAGGENSTOSS, 2018, p. 165). É nesse sentido, que a autora considera o termo indevido, uma vez que as normas da teoria do Direito Sistêmico, não são necessariamente determinadas e definidas pelo Estado, ou seja, não são Direito propriamente dito, de forma a se considerar a nomenclatura, portanto, incorreta (BAGGENSTOSS, 2018).

Alessandra Baggenstoss (2018), tece ainda, demais considerações, de forma a apresentar diferenciações e ponderações no que se refere ao estudo do paradigma sistêmico aplicado ao Direito, de forma a organizar suas indagações, conforme exposto:

a) A prática realizada pelo magistrado refere-se à prática terapêutica Constelações Sistêmicas e denominá-la como Direito Sistêmico é etimológica e epistemicamente equivocado; 
b) As Constelações Sistêmicas não se confundem com o pensamento sistêmico, visto que este é gênero e, aquelas, espécies;

c) Bert Hellinger não é o idealizador da técnica, visto que representa uma formação prático-terapêutica que alia diversos ensinamentos de variados estudiosos, variando com o prisma adotado pelo seu facilitador;

d) Há outras formas de se conceber as constelações sistêmicas que não pelo pensamento helligeriano ou exclusivamente pelas Ordens do Amor. (BAGGENSTOSS. 2018, p.167).

Apresentadas as ponderações acerca do direito sistêmico, mostra-se, em bom tempo, pontuar acerca das constelações familiares. A constelação familiar foi desenvolvida por Bert Hellinger, este nasceu na Alemanha, década de noventa, estudou pedagogia e teologia, após sua formação acadêmica iniciou os seus estudos nas áreas da psicanálise e da análise transacional, de forma a criar o modelo das constelações familiares, hoje difundido de forma global (VOLPATO, 2018). A constelação familiar caracteriza-se também "como um método multidisciplinar que tem seu suporte na terapia sistêmica ao indagar acerca das relações não aparentes que vinculam as pessoas aos sistemas familiares" (VOLPATO, 2018. p. 3). Sami Storch define também as constelações familiares de forma a associar como uma técnica que busca à harmonização das relações e dos conflitos, veja-se:

Trata-se de uma abordagem fenomenológica e sistêmica, originalmente utilizada como método terapêutico pelo alemão Bert Hellinger, que a partir das constelações familiares desenvolveu uma ciência dos relacionamentos humanos, ao descobrir algumas ordens (leis sistêmicas) que regem as relações. Essa ciência foi batizada peloseu autor com o nome de Hellinger Sciencia. O conhecimento de tais ordens (ou leis sistêmicas) nos conduz a uma nova visão a respeito dodireito e de como as leis podem ser elaboradas e aplicadas de modo a trazerem paz às relações, liberando do conflito as pessoas envolvidas e facilitando uma solução harmônica (STORCH, 2016, p. 307).

Volpato (2018) cita na definição das constelações familiares seu caráter de psicoterapia breve, de forma a poder ser empregada em diversos âmbitos profissionais:

\footnotetext{
De acordo com Possato (2008) o método denominado Constelação Sistêmica Familiar constitui uma psicoterapia do tipo breve que valoriza as emoções e as energias do inconsciente, que irão ter influência e interferir nas nossas decisões. Segundo essa perspectiva, elas influenciam e interferem nas decisões das pessoas. $\mathrm{O}$ mesmo autor destaca ainda que este método tem sido utilizado em diversos tipos detratamento, seja na busca de soluções no âmbito jurídico e organizacional, ou até mesmo, para o desenvolvimento de produtos, estratégias, soluções para criação de roteiros, divulgação e propaganda (VOLPATO, 2018, p.5)
}

O magistrado Sami Storch iniciou o ingresso das constelações familiares no judiciário pátrio na comarca de Itabuna, Bahia, o método de terapia breve foi utilizado e associado às sessões de mediação/conciliação como ferramenta "da justiça para trazer à tona as raízes ocultas do conflito/questão e os caminhos para a pacificação/solução, evidenciando-os de forma tocante e mobilizadora para as partes envolvidas" (STORCH, 2016, p. 308).

Nesse sentido, as constelações familiares seriam válidas ao âmbito do Direito, uma vez que sua técnica e sua aplicação trazem à tona uma melhor percepção da dimensão sistêmica dos conflitos, reação esta que os demais métodos adequados de solução de conflito não necessariamente atingem, ou alcançam com certa morosidade, quando comparadas às constelações sistêmicas (GIRARDI; LIPPMANN; OLDONI, 2018). Thais Souza (2020) complementa que, uma vez desveladas as dinâmicas ocultas inseridas no conflito através das constelações familiares, permitiria às partes envolvidas uma tomada de consciência adequada 
do conflito, de forma a facilitar e a incentivar soluções pacíficas e duradouras do conflito, dinâmica esta não alcançada na judicialização tradicional.

Diante do exposto, cabe novamente a ressalva de outros autores que apontam: "se distancia do senso comum de atrelamento da visão sistêmica a utilização das constelações familiares. Em realidade, as constelações familiares são uma das ferramentas base do paradigma sistêmico aplicado ao Direito." (SOUZA, 2020, p. 10). Ainda, as constelações familiares devem ser vistas como espécie, enquanto a constelação sistêmica deve ser compreendida como gênero, isto porque, constelação sistêmica é todo o conjunto de ferramentas que possibilita a identificação da origem e motivos do objeto em estudo (BAGGENSTOSS, 2018), podendo haver, portanto, aplicação da constelação sistêmica em qualquer área de estudo (empresarial, familiar, penal, escolar), podendo ou não ter incidência no Direito e ainda através de diversas técnicas sistêmicas (BAGGENSTOSS, 2018.).

Outra menção que aparenta merecer destaque, refere-se à discussão sobre os cuidados acerca da aplicação da constelação familiar pelo Poder Judiciário, bem como no âmbito do Direito em geral, visto que, trata-se de uma técnica de terapia breve, se discute sobre o profissional do Direito ser apto à aplicação desta técnica, uma vez que há limites profissionais e éticos que talvez extrapolem o seu conhecimento. Nesse sentido, elucide Alessandra Baggenstoss (2018):

\begin{abstract}
O modelo de Constelação Familiar, utilizado no Poder Judiciário Brasileiro em mediações familiares, assemelha-se fortemente com a terapia familiar de Abordagem Bioecológica, prática restrita de atuação profissional de psicólogo. Em tal abordagem, o desenvolvimento humano é observado por meio da interação de quatro núcleos inter- relacionados principais, quais sejam: o processo (e suas regras), a pessoa, o contexto e o tempo (BRONFENBRENNER; MORRIS, 1998). Assim, é destacada a interação da pessoa com o ambiente e as outras pessoas em processo recíproco e mútuo.Nessa perspectiva, é arriscado um profissional da área jurídica se arriscar no manejo de questões que extrapolem os seus conhecimentos humanos e profissionais; da mesma forma, é inadequado que um profissional da área da psicologia pretenda denominar-se afeto à área jurídica e pretenda conduzir questões jurídicas ou pedagógicas. (BAGGENSTOSS, 2018, p. 168).
\end{abstract}

Não se pode negar, contudo, que a constelação familiar consagrou grande visibilidade para o paradigma sistêmico, inclusive, no âmbito do Direito, bem como, faz-se pertinente afirmar que a prática da constelação familiar, como ferramenta de resolução de conflito associada à mediação/conciliação, está efetivamente relacionada à justiça multiportas consagrada pelo CPC, na medida que o Poder Judiciário passou a adotar outras portas, menos comuns, à pacificação dos conflitos e demandas (PELLEGRINI, 2019).

Uma vez apontadas as considerações supracitadas, se faz necessário, portanto, observar que a perspectiva sistêmica pode se transferir enquanto paradigma científico através de diversas formas e técnicas restaurativas (BAGGENTOSS, 2020).), ad exemplum, pela prática das constelações familiares, o próprio "Direito Sistêmico" (em suas diferentes acepções), ou ainda pela prática da advocacia sistêmica.

A “Advocacia Sistêmica, nada mais é do que o exercício da advocacia sob o paradigma do Pensamento Sistêmico, e seu objetivo é incluir o atendimento humanizado, olhando para a parte que está na sua frente" (BRANCA; MATTEU, 2020, p. 99). Alguns autores apontam também como causa da inserção da perspectiva sistêmica à advocacia a partir de um desconforto, por parte de muitos advogados, em relação ao "modus operandi" da profissão, no que tange a relação cliente-advogado, a dinâmica do judiciário e quaisquer outras questões relativas à essência da advocacia (PELLEGRINI, 2019). "Foi nessa linha de autorreflexão que 
se passou a pensar acerca da aplicação desse paradigma na advocacia" (PELLEGRINI, 2019, p. 6).

Mais uma vez, aparenta ser providencial demonstrar alguns apontamentos acerca da teoria sistêmica, já que, alguns autores insistem em sempre associar a dinâmica sistêmica do Direito relacionada à Bert Hellinger. Nessa zona de pensamento, Girardi, Lippmann e Oldoni (2018) afirmam que a prática da advocacia sistêmica se propaga, tendo como pilar as Leis do Amor de Bert Hellinger, nesse sentido, corroboram Dantas, Lima e Peranovich (2019, p. 81):

Para tanto, o advogado precisa conhecer a filosofia hellingeriana que consiste na utilização das técnicas das constelações familiares, como um método de terapia breve na qual traz à tona o que há de oculto naquele conflito, a partir da utilização das leis sistêmicas, conhecidas como Ordens do Amor.

Outro norte, há autores que não se reduzem apenas à perspectiva Hellingeriana, introduzindo demais técnicas e concepções à chamada Advocacia Sistêmica. Nesse âmbito, emergem "estudos visando a uma nova forma de atuação daqueles que trabalham com o Direito: como o modelo de gestão da advocacia sistêmica" (PELLEGRINI, 2019). Nesse modelo, o advogado desenvolve competências transversais e conhecimentos não específicos do Direito, como competências relacionais, negociais, organizacionais, sensoriais, dentre outras técnicas que podem ser utilizadas pelo advogado, conforme exemplifica Santos (2018, n.p.): "a advocacia sistêmica tem como bases metodológicas abordagens de: psicologia positiva, neurosemântica, programação neurolinguística, coaching sistêmico, consultoria sistêmica, points of you e constelações familiares e organizacionais".

Nesta segunda perspectiva, entende-se que na advocacia sistêmica, em primeiro lugar, a postura do profissional é de ser advogado, defensor dos interesses do cliente, não podendo, portanto, ser confundido com um conciliador, constelado ou terapeuta. O Advogado Sistêmico, portanto, é aquele que não apenas logra seu labor de forma automatizada e preso à litigância tradicional, vai além, de forma a oferecer presença em seu ofício, analisa o conflito do cliente como um todo, identificando padrões e conexões do litígio (PELLEGRINI, 2019).

Por fim, independentemente da acepção conceitual, o advogado sistêmico pode se passar também como um meio de ressignificação da advocacia, entendendo esse processo, como dar novo sentido a algo. "Nesse caso, o paradigma sistêmico aplicado a advocacia auxilia na retomada de propósito e na conversão de olhar desse profissional em sua forma de lidar e enxergar todas as conexões e fenômenos da vida próprios da dimensão jurídica" (PELLEGRINI, 2019, p. 13). Ademais, conforme pontua Marcella Santos (2019), a Advocacia Sistêmica não é um modelo fechado e está em constante construção, uma vez que demanda o desenvolvimento contínuo do advogado em competências essenciais à perspectiva sistêmica, de forma a garantir um olhar empático de todos os sistemas envolvidos no conflito.

\section{CONSIDERAÇÕES FINAIS}

Uma vez observados e analisados os paradigmas em debate até então, nota- se, em especial, acerca das moléstias inerentes ao modelo cartesiano aplicado ao Direito. As soluções apresentadas pela jurisdição, dotada de formalismo, apego exacerbado ao positivismo, ausência de celeridade, e inflexibilidade demais, vem se mostrando como uma dinâmica questionada por vezes. A acepção de justiça alcançada pela perspectiva newtoniana, não se reflete, portanto, eficiente no campo prático à realidade social hiper complexa, causando às partes envolvidas no conflito, uma prostração com a dinâmica cartesiana e sua forma de sanar o litígio.

Através dos estudos, contudo, não é possível afirmar ser a perspectiva cartesiana dispensável ao Direito, uma vez que assegura uma certa segurança jurídica à matéria, bem como 
pode ser também instrumento válido como meio de resolução de conflito. Nesse sentido, se rejeita afirmar acerca da impossibilidade de o paradigma cartesiano garantir uma solução científica e válida no campo jurídico, a questão, no entanto, se mostra preocupante, quando da crença sobre ser este método cartesiano tradicional a única via de acesso à justiça, sob pena de sua ineficiência.

Portanto, tendo em vista os argumentos apresentados à pesquisa, a perspectiva sistêmica se mostra também como meio eficiente de acesso à justiça, uma vez que sua organização garante diferentes formas e meios de acesso à justiça. A análise criteriosa e ampla desse método permite um entendimento a fundo sobre o conflito, compreendendo não apenas os ditames legais envolvidos, mas também as subjetividades intrínsecas ao caso concreto, podendo, dessa forma, direcionar a uma acepção de justiça mais coerente e eficaz às partes conflitantes.

A pesquisa pretendeu demonstrar que a concepção de Justiça Multiportas, estimulada pela legislação pátria pela Lei 13.105 e pela Resolução 125 do Conselho Nacional de Justiça, sintonizam com o preceito acerca da necessidade de novas formas de acesso à justiça, de forma a emergir o conceito dos métodos adequados de solução de conflito, como a mediação, a conciliação e a arbitragem como formas fidedignas de acesso à justiça. Porém, conforme exposto ao longo da pesquisa, o paradigma sistêmico aparenta não surgir em virtude, e nem se resumir, aos métodos supracitados, havendo, portanto, necessidade ainda de se aprofundar com intensidade sobre novos estudos acerca da perspectiva sistêmica.

Ocorre que o movimento de implementação do paradigma sistêmico aplicado ao direito aparenta ser ainda efêmero, portanto, demonstra ser, portanto, um conceito em constante construção. Nada impede, contudo, que as devidas diferenciações e métodos, como o Direito Sistêmico, a Advocacia Sistêmica e as Constelações Familiares sejam alvo de análise e diferenciação, a fim de se demonstrar a capacidade e a eficiência dessas perspectivas à ceara jurídica.

\section{REFERÊNCIAS}

ALVES, João Bosco da Mota. Teoria geral de sistemas: em busca da interdisciplinaridade. Florianópolis: Instituto Stela, 2012.

AMORIM, Silva; NETO, Sertório. O que é um paradigma? Revista de Ciências Humanas, Florianópolis, Volume 45, n. 2, p. 345-354, out. 2011.

ANDRADE, Aurélio L. O Curso do pensamento sistêmico. São Paulo: Digital Publish \& Print, 2017. Ebook Kindle.

ARAÚJO, Fábio Roque da Silva. A ruptura do paradigma cartesiano e alguns dos seus reflexos jurídicos. Revista Centro de Estudos Judiciários, Brasília, Ano XIII, n. 46, p.7886, jul./set. 2009.

BAGGENSTOSS, Grazielly Alessandra. Conexões entre pensamento sistêmico, constelações sistêmicas e direito sistêmico. Revista Cidadania e Acesso à Justiça, V. 4, n. 1, p. 153-173, jan./jun. 2018.

BORGES, Éderson et al. As câmaras privadas de mediação e conciliação como alternativa para a solução negocial de conflitos de interesses. Constituição e Justiça: Estudos e Reflexos, v.1, n.1, 2017. Disponível em: 
http://periodicos.unibave.net/index.php/constituicaoejustica/article/view/119/103\#. Acesso em: 28 de abr. de 2021.

BRANCA, Carla Alessandra; MATTEU de Douglas. O futuro humanizado do direito. São Paulo, Literare Books Internacional, 2020. E-book Kindle.

BRASIL. [Constituição (1988)]. Constituição da República Federativa do Brasil de 1988. Brasília, DF: Presidência da República [2021a]. Disponível em:

http://www.planalto.gov.br/ccivil_03/constituicao/constituicao.htm. Acesso em: 2 de fev. de 2021.

BRASIL. Lei n ${ }^{\circ} 13.105$ de 16 de março de 2015. Institui o Código de Processo Civil de 2015. Diário Oficial da União, Brasília, DF, [2021b]. Disponível em:

http://www.planalto.gov.br/ccivil_03/_ato2015-2018/2015/lei/113105.htm. Acesso em: 12 de jan. de 2021.

BRASIL. Lei n ${ }^{\circ} 13.140$, de 26 de junho de 2015. Dispõe sobre a mediação entre particulares como meio de solução de controvérsias e sobre a autocomposição de conflitos no âmbito da administração pública. [2015]. Disponível em:

http://www.planalto.gov.br/ccivil_03/_ato2015-2018/2015/lei/113140.htm. Acesso em 01de Jan. de 2021.

BRASÍLIA. Resolução n ${ }^{\circ} 125$ de 2010. Dispõe sobre a Política Judiciária Nacional de tratamento adequado dos conflitos de interesses no âmbito do Poder Judiciário e dá outras providências. Brasília, DF, 2010. Disponível em: https://www.cnj.jus.br/wp-

content/uploads/2011/02/Resolucao_n_125-GP.pdf. Acesso em: 05 de jan. de 2021.

BUNN, Maximiliano Losso. "Por um novo modelo de jurisdição: releitura do conceito de atividade jurisidicional na sociedade contemporânea". Revista do CEJUR TJSC. Prestação Jurisdicional, v. 1, n. 03, p. 11 - 24, dez. 2015.

CAPRA, Fritjof. A visão sistêmica da vida: uma concepção unificada e suas implicações filosóficas, políticas, sociais e econômicas. Tradução: Mayra Teruya Eichemberg, Newton Roberval Eichemberg. São Paulo: Cultrix, 2014.

CAPRA, Fritjof. O ponto de mutação: a ciência, a sociedade e a cultura emergente. São Paulo: Cultrix, 2012.

COELO, Bruna Vianna de Almeida; MENDES, Marisa Schmitt Siqueira. O novo código de processo civil e o sistema de justiça multiportas. II congresso catarinense de direito processual civil. Ago./set. 2016, Santa Catarina. Anais. SC: Univali, 2016. Disponível em: https://siaiap32.univali.br/seer/index.php/accdp/article/view/10194. Acesso em: 02 de abr de 2021.

DAMASCENO, Mariana; MACEDO, Elaine Harzheim. Sistema multiportas e métodos integrados de resolução de conflitos. Porto Alegre: EDIPUCRS, 2018. Disponível em: http://www.pucrs.br/edipucrs/ISBN 978-85-397-1137-6. Acesso em 20 de jan. de 2021. 
GIRARDI, Maria Fernanda Gulmenin, OLDONI, Fabiano, LIPPMANN, Márcia Sarubbi. Direito Sistêmico: aplicação das leis sistêmicas de Bert Hellinger ao Direito de Família e ao Direito Penal. 2. ed. Joinville, SC: Manuscritos Editora, 2018

GRAÇA, João Wilame Coelho. Fundamentos histórico-filosóficos do direito no ocidente: a influência do paradigma cartesiano na formação do pensamento jurídico. Revista Diálogos Acadêmicos, Fortaleza, n. 1, v. 1, jan./jun. 2012.

LIPPMANN, Márcia Sarubbi; OLDONI, Everaldo Luiz, OLDONI, Fabiano. Justiça Restaurativa Sistêmica. Joinville, SC: Manuscritos Editora, 2018.

LOPES JUNIOR, Aury. Introdução crítica ao processo penal: fundamentos da instrumentalidade constitucional. 4. ed. Rio de Janeiro: Lumen Juris, 2006.

MENDES, Regina Lúcia T. Princípio da verdade real no processo judicial brasileiro. Revista SJRJ, Rio de Janeiro, v. 17, n. 29, p. 321-341, dez. 2010.

PARADIGMA In: Dicionário Priberam da Língua Portuguesa, 2021, disponível em: https://dicionario.priberam.org/Parad\%C3\%ADgma. Acesso em 28 de mar. de 2021.

PELLEGRINI, Carolina Portella. "O pensamento sistêmico aplicado à advocacia: um caminho para a sua ressignificação". Revista Latino-Americana de Estudos em Cultura e Sociedade, V. 05, ed. especial, abr., 2019, artigo nº 1139, 2019.

PELLEGRINI, Carolina Portella. SIMIONI, Fabiane. "A crise da jurisdição no estado moderno, o novo Código de Processo Civil e o marco legal da mediação". Juris, Revista da Faculdade de Direito, Rio Grande, v. 23, p. 123-139, 2015.

RUZON, Bruno. Do verdadeiro ao convincente no Direito Constitucional. Âmbito Jurídico. 2011. Disponível em: https://ambitojuridico.com.br/cadernos/direito- constitucional/doverdadeiro-ao-convincente-no-direito-constitucional/\#_ftn25. Acesso em: 15 de nov. de 2020.

SALES, Lilia Maia de Morais; CHAVES, Emmanuela Carvalho Cipriano. Mediação e conciliação judicial - a importância da capacitação e de seus desafios. Sequência (Florianópolis), Florianópolis, n. 69, p. 255-279, Dec. 2014. Disponível em: http://www.scielo.br/scielo.php?script=sci_arttext\&pid=S217770552014000200011\&lng=en\&nrm=iso . Acesso em: 28.Apr. 2021

SANTOS, Marcella. Advocacia Sistêmica - Exercício estratégico, humanizado e consensual. Disponível em https://blog.sajadv.com.br/advocacia-sistemica/. Acesso em: 05 de ago. de 2020.

SILVA, Érica Barbosa e. Conciliação e mediação nas serventias extrajudiciais. 2018. Disponível em: https://www.conjur.com.br/2018-abr-09/erica-silva-conciliacao- mediacaoserventias-extrajudiciais. Acesso em: 28 de abr. de 2021.

SOUZA, Thais Diniz Coelho. Método alternativo de solução de conflitos e mudança paradigmática: a que veio o direito sistêmico? Conteúdo Jurídico. 2020. Disponível em: https://www.conteudojuridico.com.br/consulta/artigos/54792/mtodo-alternativo- de-soluo-de- 
conflitos-e-mudana-paradigmtica-a-que-veio-o-direito-sistemico. Acesso em: 11 de nov. de 2021.

STORCH, Sami. Direito sistêmico: a resolução de conflitos por meio da abordagem sistêmica fenomenológica das constelações familiares. Entre aspas: revista da Unicorp. Vol. 5, jul. 2016, p. 305-3016. Disponível em https://direitosistemico.wordpress.com/2017/09/22/artigodescreve-modelo-original- de-pratica-de-constelacoes-na-justica-e-aplicabilidade-do-direitosistemico/.Acesso em: 01 de mar. de 2021.

STORCH, Sami. O direito sistêmico: quando o reconhecimento das leis sistêmicas promove conciliação, p. 177/186 in Justiça Restaurativa: caminhos de pacificação social. org. Marcelo L. Pelizzoli, Editora UFPE, Recife, 2016.

THEODORO JR, Humberto. Curso de Direito Processual Civil - Teoria geral do direito processual civil e processo de conhecimento - vol. I - Rio de Janeiro: Forense, 2019.

VALADÃO, Rodrigo Borges. A curvatura do espaço jurídico (Lições de física moderna aplicadas à ciência do Direito), Revista Direito Processual Geral, Rio de Janeiro, 2002.

VASCONCELLOS, Maria José Esteves. Pensamento Sistêmico o novo paradigma da ciência. $11^{\mathrm{a}}$ Edição, Campina, Ed. Papirus, 2018. 